\title{
THE SIMULATION ANALYSIS OF TOOL FLANK WEAR BASED ON CUTTING FORCE
}

\author{
Heyao Shen ${ }^{1}$, Minghong Wang ${ }^{2}$ \\ ${ }^{1}$ Shanghai University of Engineering Science, China, Shanghai 201620 \\ ${ }^{2}$ Shanghai University of Engineering Science, China, Shanghai 201620
}

\begin{abstract}
In the process of cutting, cutting tool wear has an important influence on the surface quality of the work piece, therefore, it is of great significance for the research of tool wear detection. In this paper, this work focuses on researching relationship between cutting force and tool flank wear. In different experiment conditions, the consistency of the results of simulation and experiment results was obtained through the comparative analysis between the two. It is a complex problem that cutting tool wear and measuring process and not easy to get the accurate ideal results by experiment, the simulation experiment has the characteristics of simple and easy to operate and the result is diminutively influenced by complex factors, therefore, it is the primary method to carry out this work by simulation experiment. In this paper, it is mainly investigated into the simulation analysis of the tool flank wear. The specific content of the simulation experiment is explaining the causation for the tool flank wear through the analysis of the temperature field at the tip and obtaining the data of cutting force in different tool flank wear $(10,100,200,300 u m)$. The empirical cutting force model was established through multiple regression analysis and the tool flank wear prediction model was reversed and gained by analysis of the results of simulation experiments.
\end{abstract}

Keywords: Tool Flank Wear; Cutting Force; Simulation

\section{INTRODUCTION}

Tool wear affects the quality of workpiece surface, dimensional accuracy, tool life ,machining costs and so on, so the research topic of tool wear on-line detection is of great significance. The method of on-line monitoring of tool wear divided into direct and indirect monitoring of two methods[1-4],the method of direct monitoring mainly include optics, radioactive elements and direct contact with the monitoring method,the method of indirect monitoring is mainly established based on the correlation among the acoustic emission signals, the force, the motor, the vibration and the noise signals, the key dimensional deviation and tool wear,realizing tool wear on-line detection by monitoring these signals.In order to achieve the establishment of tool wear model,the regression algorithm of LS-SVM [5], the algorithm of Hilbert-Huang transformation [6], the discrete element method model [7], the neural network and genetic algorithm [8], the continuous hidden Markov model [9], Taguchi method [10], fractal methods [11], Simulation approaches [12] and so on are applied to the process of building the tool wear model in numerous studies on the tool wear.

In this paper,the impact of the relationship between cutting force and cutting parameters (cutting speed,depth of cut and feed rate)will be researched through simulation and experimental analysis.The simulation and experimental results are consistent by comparative analysis.Then,the relationship between tool flank wear and the cutting force is studied by simulation experiment under the different preset tool flank wear(10,100,200,300um).The cutting force experience model is set up after obtaining simulation data by multiple regression analysis and the tool flank wear VB Mathematical Model about cutting parameters and cutting force is built.So the tool flank wear magnitude can be monitored indirectly through on-line measurement of cutting force.

\section{MODELLING OF ORTHOGONAL CUTTING PROCESS BY SIMULATION}

\subsection{Modelling of Orthogonal Cutting}

Numerical simulation of the cutting process can provide detailed results of process variables such as stress, strain, cutting force, temperature which are not easy to be measured with today's technology. There are two traditional finite element approaches which the Lagrangian and the Eulerian formulations are used in cutting process simulation[13].The finite element approac of the Lagrangian formulation is commonly used in simulation process.And those of the Eulerian formulation is no need to define a failure criterion, but it is not easily adapTable-to model the unconstrained flow of the material at the free boundaries as the chip formation reported in advance by Movahhedy[14].With the development of computer technology, an alternative approach that could combine the advantage of both the Lagrangian and the Eulerian formulations,called the arbitrary Lagrangian-Eulerian (ALE) formulation, reported by Al-Athel and Gadala [15].

In this paper,a 2D orthogonal cutting model based on the ALE approach is employed, which can be seen in Fig-1.This model is a very usefully method to simulate the cutting 
process and to be used to finish cutting chip forming by relying on defining material failure,therefore the Eulerian simulation with the difficulty that needing to determine the chip shape in advance was effectively avoided and this method can save time compared with other simulation method.We can determine the magnitude of the cutting force under different cutting parameters by this model.Fig-1 shows that the location of the relationship between tool and workpiece,the geometry of cutting speed and depth of the cut,the tool is fixed and the rake angle is and the clearance angle is .

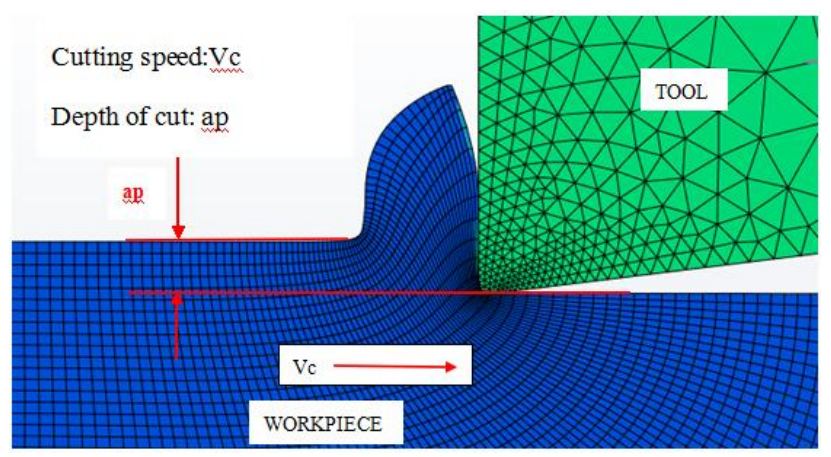

Fig-1 Modeling of orthogonal cutting

\subsection{Material Properties}

To analyze the cutting process with different cutting parameters and tool blank wear, it is necessary to introduce a material flow stress model to describe the material behavior. Johnson - Cook plasticity model used in adiabatic instantaneous dynamic simulation can be used with Johnson - Cook the dynamic failure and also with progressive damage and failure models, usually presented with equation (i) [13]:

$$
\bar{\sigma}=\left(A+B \bar{\varepsilon}^{n}\right)\left(1+C \ln \frac{\dot{\bar{\varepsilon}}}{\dot{\bar{\varepsilon}}_{0}}\right)\left(1-T^{* m}\right)
$$

And the is defined as:

$$
T^{*}=\frac{T-T_{r}}{T_{m}-T_{r}}
$$

Where $\bar{\sigma}$ is the equivalent flow stress, $\bar{\varepsilon}$ is the equivalent plastic strain, $\dot{\bar{\varepsilon}}$ the equivalent plastic strain rate, ${ }^{\dot{\bar{\varepsilon}}_{0}}$ the reference strain rate which equals $1 s^{-1}$. The material characteristics are defined as Table-1and material properties for the workpiece and tool defined as Table-2.Tm and Tr are the material melting temperature $\left(1460{ }^{\circ} \mathrm{C}\right)$ and reference ambient temperature $\left(20{ }^{\circ} \mathrm{C}\right)$.

Table--1: Johnson-Cook model constants for IASI 1045

\begin{tabular}{|l|l|l|l|l|}
\hline $\mathrm{A}(\mathrm{MPa})$ & $\mathrm{B}(\mathrm{MPa})$ & $\mathrm{C}$ & $\mathrm{n}$ & $\mathrm{m}$ \\
\hline 553.1 & 600.8 & 0.0134 & 0.234 & 1.0 \\
\hline
\end{tabular}

Table--2: Material properties for the workpiece and tool

\begin{tabular}{|l|l|l|}
\hline Material properties & Workpiece & Tool \\
\hline Material properties & AISI 1045 & CBN \\
\hline Young's modulus $(\mathrm{GPa})$ & 210 & 587 \\
\hline Poisson's ratio & 0.3 & 0.13 \\
\hline Conductivity $\left(\mathrm{Wm}^{-10} \mathrm{C}^{-1}\right)$ & 53.9 & 44 \\
\hline Specific heat $\left(\mathrm{Jkg}^{-10} \mathrm{C}^{-1}\right)$ & 420 & 750 \\
\hline $\begin{array}{l}\text { Thermal expansion } \\
\text { coefficient }\left({ }^{0} \mathrm{C}^{-1}\right)\end{array}$ & $1.2 \times 10^{-6}$ & $4.7 \times 10^{-6}$ \\
\hline
\end{tabular}

\section{RESULTS AND DISCUSSION}

\subsection{The Results of Cutting Force Experiments}

The experiment of cutting force is being on the CA6140 cutting AISI1045 with CBN tools.In the cutting process,measuring the magnitude of the cutting force under the different cutting parameters(such as cutting speed,depth of cut and feed rate).The cutting speed set for $6.54,10.28$ and $18.41 \mathrm{~m} / \mathrm{min}$,depth of cut set for $0.5,0.7$ and $1.0 \mathrm{~mm}$,feed rate set for $0.1,0.15,0.2$ and $0.24 \mathrm{~mm} / \mathrm{rev}$.Experiment one, set feed rate as independent variables, experiment II,setting cutting speed as independent variables and three set the depth of cut as independent variables,measuring the magnitude of the cutting force under the different cutting parameters.

Simulation experiment I,establishment of orthogonal cutting model of the machining based on the different cutting parameters in the experiment of cutting force.

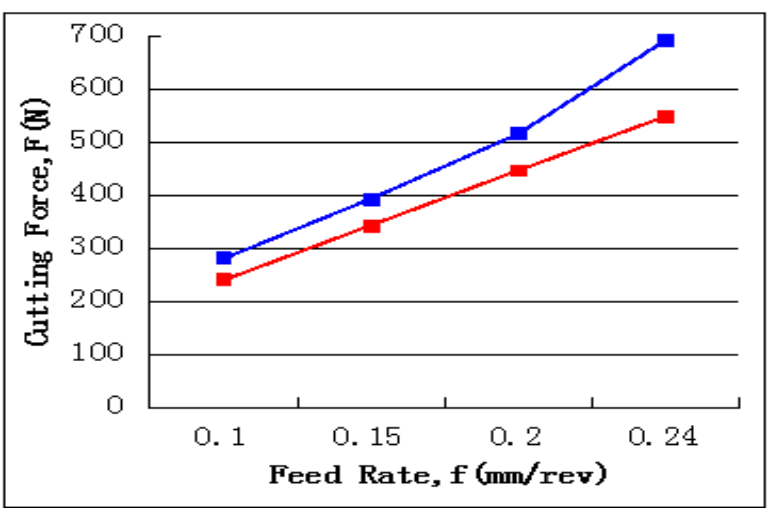

(a) $\mathrm{Vc}=10.28 \mathrm{~m} / \mathrm{min}, \mathrm{ap}=1.0 \mathrm{~mm}$, f as the independent variable, the cutting force variation

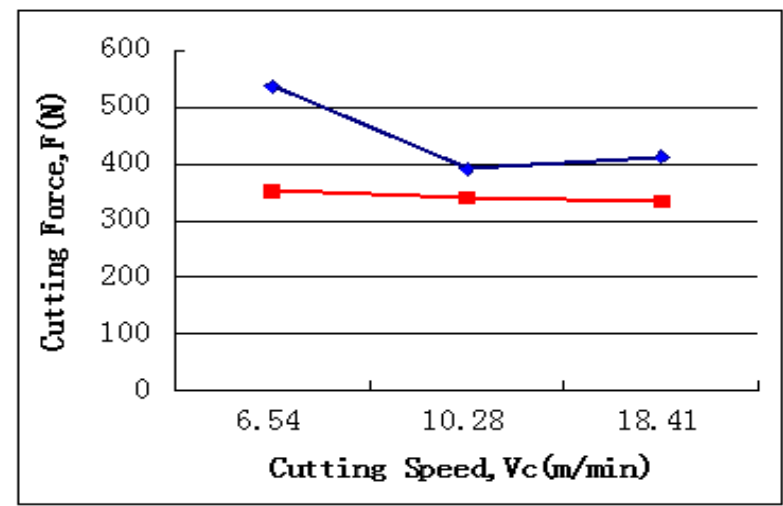

(b) $\mathrm{ap}=1.0 \mathrm{~mm}, \mathrm{f}=0.15 \mathrm{~mm} / \mathrm{rev}, \mathrm{Vc}$ as the independent variable, the cutting force variation 


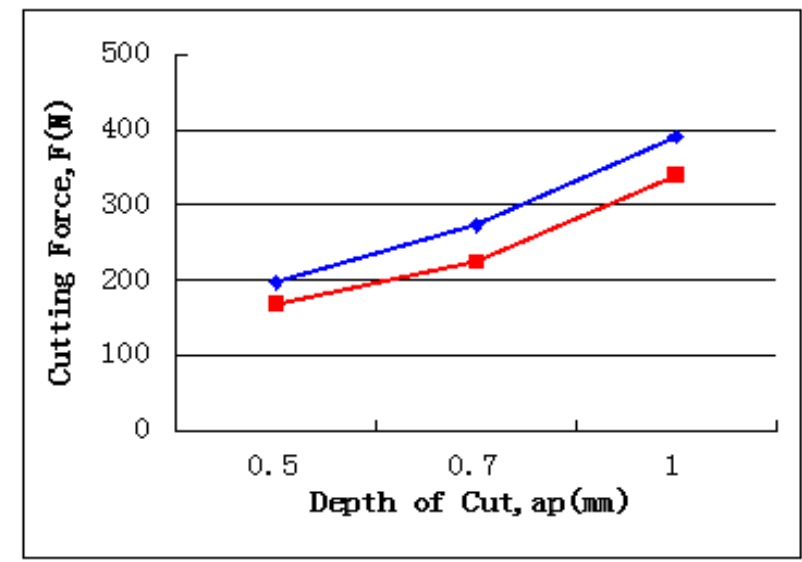

(c) $\mathrm{Vc}=10.28 \mathrm{~m} / \mathrm{min}, \mathrm{f}=0.15 \mathrm{~mm} / \mathrm{rev}$, ap as the independent variable, the cutting force variation

$$
\rightarrow \text { Experimental Data } \rightarrow \text { Simulation Data }
$$

Fig- 2 Cutting force with different cutting parameters

\subsubsection{Experimental Data Analysis}

The results of experiment of cutting force and simulation experiment I are drawn by Fig-2(a), the maximum deviation is $20.84 \%$, the minimum deviation is $13.04 \%$, the average deviation is $15.51 \%$; The maximum deviation is $46.18 \%$, the minimum deviation is $13.04 \%$, the average deviation is $19.13 \%$ are drawn by Fig-2(b); The maximum deviation is $17.85 \%$, the minimum deviation is $13.04 \%$, the average deviation is $14.94 \%$. From this three single factor experiments,all the average deviation is less than $20 \%$ are drawn by Fig-2(c).

\subsubsection{Deviation Analysis}

The finite element model is the ideal model, and the tool wear is not considered, but the actual machining process is wear and tear, which leads to the simulation;The artificial operation causes the actual measured data is too large, such as the tool setting is not accurate, not accurate measurement calibration,etc.;Environmental deviation leading to the actual measurement data is larger, for example, machine tool vibration, environmental temperature and cutting conditions,etc.; The actual cutting material and finite element simulation of the material data is inconsistent, resulting in the existence of deviation. For example, the expansion of materials, hardness and elastic/plastic coefficient,etc.

From this three groups of linear charts that we can get the following summary:Simulation and experimental data have the same trends; The results of simulation and experimental data are consistent when taking into account the presence of experimental deviations. Therefore, it is worthwhile to analyze the simulation data,in other words, can use simulation data instead of experimental data to find related rules between the independent variables and the dependent variable in some studies .

\subsection{The Results of Simulation of Tool Blank Wear}

Based on the experimental data,it can be possible to predict the tool life under the equal conditions in the cutting experiment also in the similar conditions in cutting process.Considering the fact that in cutting based on different speeds, while the wear causation is similar, flank wear reaches to a specific magnitude of VB at different cutting times while the shapes of worn tools are approximately similar, available models for any cutting speed are run until the mechanical-thermal steady states are reached[17]. The magnitude of cutting tool blank wear were preset based on this idea.Fig- 3 shows that four different sets of tool flank wear (10um,100um,200um,300um).

Get the mathematical model of cutting force by cutting simulation under the prediction of different cutting tool blank wear.

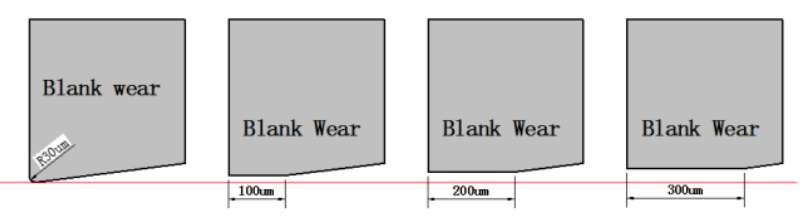

Fig- 3 Cutting edge geometries with different cutting tool blank wear

Simulation experiment II,establishment on orthogonal cutting model of the machining under the different cutting tool blank wear with different cutting parameters.The cutting tool blank wear set for 10,100,200and300um(Cutting edge geometries as shown in Fig- 3 ), The cutting speed set for $10,15,20 \mathrm{and} 25 \mathrm{~m} / \mathrm{min}$, depth of cut set for $0.5,0.7,0.9$ and $1.1 \mathrm{~mm}$,feed rate set for $0.1,0.15,0.2$ and $0.25 \mathrm{~mm} / \mathrm{rev}$.By establishment of orthogonal cutting machining model based on simulations, the output (temperature, energy, force) can be defined in the simulation software.

Table-3 Simulation experiment variable

\begin{tabular}{|l|l|l|l|l|}
\hline $\begin{array}{l}\text { No. } \\
\text { Variable }\end{array}$ & $\begin{array}{l}\text { Vc } \\
(\mathrm{m} / \mathrm{s})\end{array}$ & $\begin{array}{l}\mathrm{A}_{\mathrm{p}} \\
(\mathrm{mm})\end{array}$ & $\begin{array}{l}\mathrm{F} \\
(\mathrm{mm} / \mathrm{rev})\end{array}$ & $\begin{array}{l}\text { VB } \\
(\mathrm{um})\end{array}$ \\
\hline 1 & 10 & 0.5 & 0.1 & 10 \\
\hline 2 & 15 & 0.7 & 0.15 & 100 \\
\hline 3 & 20 & 0.9 & 0.20 & 200 \\
\hline 4 & 25 & 1.1 & 0.25 & 300 \\
\hline
\end{tabular}

\subsection{Cause of the Cutting Tool Flank Wear}

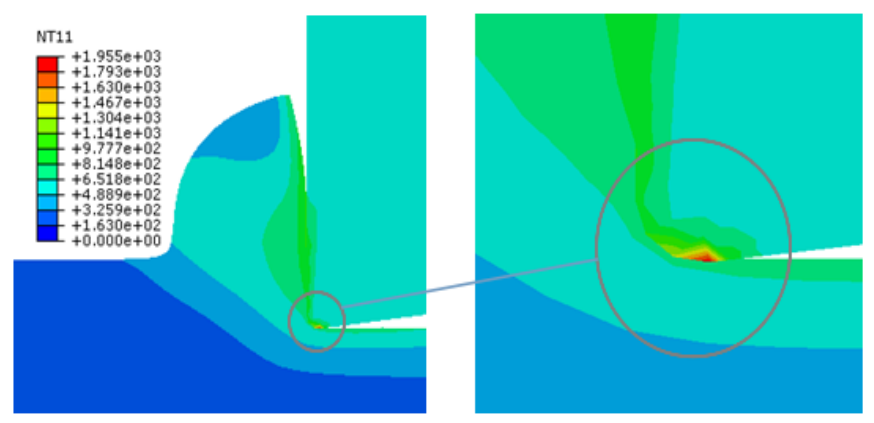

Fig- 4 Node temperature in tool nose 
Fig- 4 shows that the node temperature in tool nose,getting it that the high temperature at the tool nose in the cutting model.The tool nose where accompanied with high temperature and wear the fastest under the the friction effect was learned from the manual[16].High temperature accompanied with poor heat dissipation condition, this is the main idea in cutting tool blank wear.

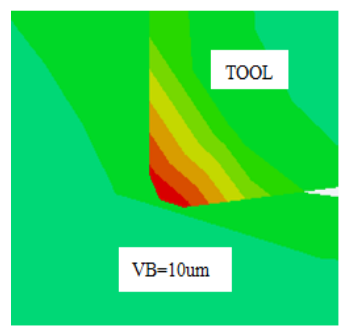

(a)

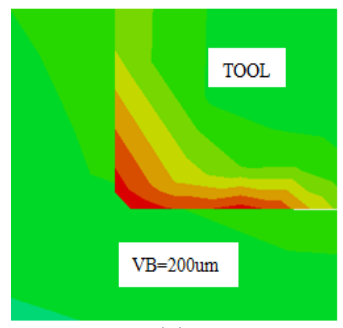

(c)

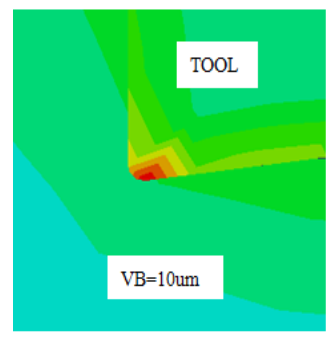

(e)

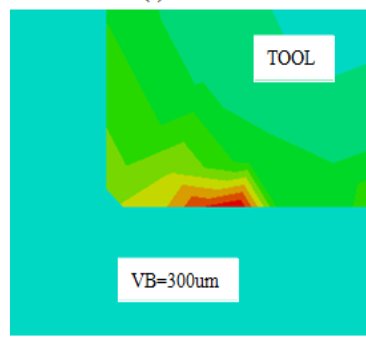

(g)

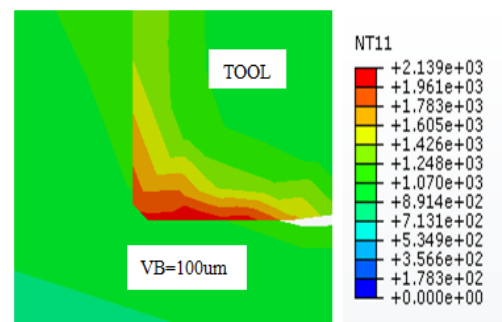

(b)

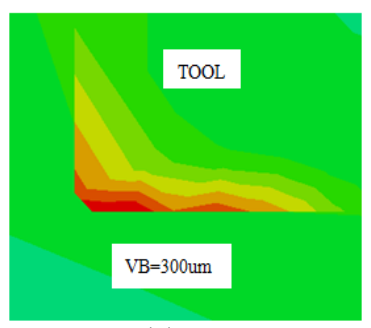

(d)

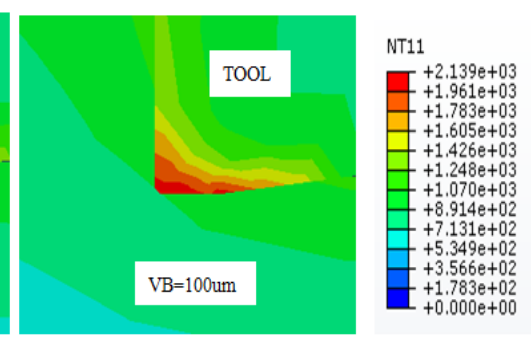

(f)

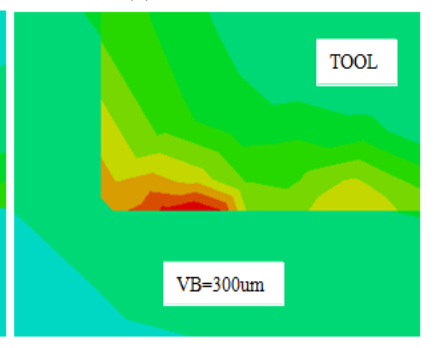

(h)
Fig- 5 a-d shows the node temperature in tool nose when the cutting time was $1.5 \mathrm{e}-4 \mathrm{~S}$ under the conditions that $\mathrm{ap}=0.7 \mathrm{~mm}, \mathrm{Vc}=20 \mathrm{~m} / \mathrm{s}, \mathrm{f}=0.15 \mathrm{~mm} / \mathrm{rev}$ and

$\mathrm{VB}=10,100,200$ and $300 \mathrm{um} ; \mathrm{e}-\mathrm{h}$ shows the node temperature in tool nose when the cutting time was $5.85 \mathrm{e}-4 \mathrm{~S}$ under the conditions that ap $=1.1 \mathrm{~mm}, \mathrm{Vc}=10 \mathrm{~m} / \mathrm{s}, \mathrm{f}=0.25 \mathrm{~mm} / \mathrm{rev}$ and $\mathrm{VB}=10,100,200$ and $300 \mathrm{um}$

Fig- 5(a-d,e-f)shows that the greater the cutting tool flank wear, the greater the tool nose high temperature area.The heat at the tool nose diffused more and more slowly with the increase of tool wear area.Cutting tool flank wear affect the quality of workpiece, it is necessary to replace the cutting tools under the conditions of serious tool flank wear.In order to improve tool life,change the cutting Angle and cutting parameters in time to reduce tool wear.

\subsection{Prediction Model of Tool Flank Wear}

Table-4 The results of Simulation experiment II

\begin{tabular}{|c|c|c|c|c|c|}
\hline $\begin{array}{c}\text { Variable } \\
\text { No. }\end{array}$ & $\begin{array}{c}\mathrm{A}_{\mathrm{p}} \\
(\mathrm{mm}) \\
\mathrm{A}\end{array}$ & $\begin{array}{c}\mathrm{Vc} \\
(\mathrm{m} / \mathrm{min}) \\
\mathrm{B}\end{array}$ & $\begin{array}{c}\mathrm{F} \\
(\mathrm{mm} / \mathrm{rev}) \\
\mathrm{C}\end{array}$ & $\begin{array}{l}\mathrm{VB} \\
\text { (um) } \\
\mathrm{D}\end{array}$ & $\begin{array}{c}\text { Cutting } \\
\text { Force }(\mathrm{N})\end{array}$ \\
\hline 1 & 0.5 & 10 & 0.1 & 0 & 221 \\
\hline 2 & 0.5 & 15 & 0.15 & 100 & 145 \\
\hline 3 & 0.5 & 20 & 0.2 & 200 & 204 \\
\hline 4 & 0.5 & 25 & 0.25 & 300 & 260 \\
\hline 5 & 0.7 & 10 & 0.15 & 300 & 250 \\
\hline 6 & 0.7 & 15 & 0.1 & 0 & 215 \\
\hline 7 & 0.7 & 20 & 0.25 & 200 & 370 \\
\hline 8 & 0.7 & 25 & 0.2 & 100 & 255 \\
\hline 9 & 0.9 & 10 & 0.2 & 300 & 368 \\
\hline 10 & 0.9 & 15 & 0.25 & 200 & 450 \\
\hline 11 & 0.9 & 20 & 0.1 & 100 & 185 \\
\hline 12 & 0.9 & 25 & 0.15 & 0 & 224 \\
\hline 13 & 1.1 & 10 & 0.25 & 100 & 556 \\
\hline 14 & 1.1 & 15 & 0.2 & 0 & 436 \\
\hline 15 & 1.1 & 20 & 0.15 & 300 & 333 \\
\hline 16 & 1.1 & 25 & 0.1 & 200 & 155 \\
\hline $\mathrm{K}_{1}$ & 830 & 1395 & 776 & 1096 & \\
\hline $\mathrm{K}_{2}$ & 1090 & 1246 & 952 & 1141 & \\
\hline $\mathrm{K}_{3}$ & 1227 & 1148 & 1263 & 1179 & \\
\hline $\mathrm{K}_{4}$ & 1480 & 894 & 1636 & 1211 & \\
\hline $\mathrm{k}_{1}\left(=\mathrm{K}_{1} /\right.$ & 207.5 & 348.75 & 194.00 & 274.0 & \\
\hline $\mathrm{k}_{2}\left(=\mathrm{K}_{2} /\right.$ & 272.5 & 311.50 & 238.00 & 285.2 & \\
\hline $\mathrm{k}_{3}\left(=\mathrm{K}_{3} /\right.$ & 306.7 & 287.00 & 315.75 & 294.7 & \\
\hline $\mathrm{k}_{4}\left(=\mathrm{K}_{4} /\right.$ & 370.0 & 223.50 & 409.00 & 302.7 & \\
\hline Range & 162.5 & 125.25 & 215.00 & 28.75 & \\
\hline $\begin{array}{l}\text { Optimal } \\
\text { case }\end{array}$ & A1 & B4 & $\mathrm{C} 1$ & D1 & \\
\hline
\end{tabular}

Simulation experiment data analysis are

Table-4 shows that the results of Simulation experiment II.K1 line of four numbers are the first level of the test factor A,B,C,D where the magnitude of the corresponding the sum of cutting forces.For example,for factor A,it's the first horizontal arrangement in No. 1,2,3,4trials,cutting force corresponding magnitudes of $221,145,204,260$, the sum is 830 ;for factor B,it's the first horizontal arrangement in No. $1,5,9,13$ trials,cutting force corresponding magnitudes of $221,250,368,556$, the sum is 1395 ;for factor C,it's the first horizontal arrangement in No. 1,6,11,16 trials,cutting force corresponding magnitudes of $221,215,185,115$, the sum is 776 ; for factor D,it's the first horizontal arrangement in No. $1,6,12,14$ trials,cutting force corresponding magnitudes of $221,215,224,436$, the sum is 1096 . The line of $\mathrm{K} 2, \mathrm{~K} 3, \mathrm{~K} 4$ so do it.k1,k2,k3,k4 are the average of the corresponding horizontal.In the same column,among the number of $\mathrm{k} 1, \mathrm{k} 2$, $\mathrm{k} 3$, k4obtained the result of the greatest number minus the smallest, called Range. The bigger the Range is,the bigger 
the influence are.So the influence factors of the minimum for VB.

Considering the influence of cutting speed(Vc),depth of cut(ap),feed rate(f) and cutting tool blank wear (VB), assuming the form of a cutting force model:

$$
F=C a_{p}^{x} V c^{y} f^{z} V B^{m}
$$

Based on the results of Simulation experiment II,the result of multivariate regression analysis was:

$$
F=3609 a_{p}^{0.671} V c^{-0.338} f^{0.771} V B^{-0.038}
$$

So the VB(the tool flank wear prediction model) is:

$$
V B=\left[\frac{F}{3609 a_{p}^{0.671} V c^{-0.338} f^{0.771}}\right]^{-\frac{500}{19}}
$$

In order to verify the rationality of the empirical formula of cutting force, two groups of the simulation experiments were sett up and the experimental conditions were $\mathrm{ap}=0.7 \mathrm{~mm}, \mathrm{Vc}=10 \mathrm{~mm} / \mathrm{s}, \mathrm{f}=0.2 \mathrm{~mm} / \mathrm{rev}, \mathrm{VB}=400 / 500 \mathrm{um}$, and the results were obtained as shown in Table-5,

Table5 The results of verification experiment

\begin{tabular}{|l|l|l|l|}
\hline Assortments & $\begin{array}{l}\text { Simulation } \\
\text { cutting } \\
\text { force }\end{array}$ & $\begin{array}{l}\text { Calculatio } \\
\text { n cutting } \\
\text { force }\end{array}$ & Deviation \\
\hline VB=400um & 308 & 332 & $4.55 \%$ \\
\hline VB=500um & 321 & 341 & $5.61 \%$ \\
\hline
\end{tabular}

From Table-5, it can be concluded the empirical formula of cutting force is reasonable,judged the magnitude of the tool flank wear based on the magnitude of the on-line measurement of cutting force by formula (3).

\section{CONCLUSION}

In this paper, the consistency of the simulation results with the experimental results have been verified by the orthogonal cutting model, the causation for the wear of the flank wear been introduced, the tool flank wear been preset,the data of cutting force were obtained through simulation experiments in different tool flank wear amount, finally,empirical cutting force model was established through multiple regression analysis, the tool flank wear prediction model was reversed and gained.Because it is not easy to measure the data of tool flank wear in the cutting process,in other words, it is not easy to do the blade flank wear experiments.In order to study the influence on the magnitude of the cutting force in the cases of the differences of cutting tool blank wear,pre-determine the data of tool flank wear(as shown in Fig-3).Then,confirm the magnitude of the cutting force under different cutting parameters and cutting tool flank wear data through numerical simulation experiment.Finally,obtained some results through analysis of numerical simulation experiment data, as follows: (i)The results of numerical simulation with results of real experiments are consistent by analysis of the results of cutting force experiments.

(ii)The heat diffusion is slow at the tool nose with the increase of tool wear area.In order to improve tool life,reducing tool wear by changing the cutting angle and cutting parameters in time to reduce tool wear.

(iii)To determine the magnitude of the VB data by judging the magnitude of the cutting force under the experimental conditions of good cutting conditions and cutting force measurement.

(iv) To gain cutting force experience formula by the result of multivariate regression analysis based on the results of Simulation experiment II, as shown in the formula (2).

\section{ACKNOWLEDGEMENTS}

The authors would like to thank Shanghai University of Engineering Science (Project Code: 14KY0107) for providing financial support for the project, and the reviewers for their suggestions. Also, the authors would like to thank the editor and the reviewers for their constructive comments and suggestions which improved the quality of this paper.

\section{REFERENCES}

[1]. M.S.H. Bhuiyan, I.A. Choudhury, M. Dahari.Monitoring the tool wear, surface roughness and chip formation occurrences using multiple sensors in turning[J].Journal of Manufacturing Systems 33 (2014) 476-487

[2]. Na JIA,Xueting MA.Discussion on the Research of Tool Wear On-line Monitoring Technology[J].Value Engineering. [3]. Francois Ducobua, Pedro-Jose Arrazola, Edouard Riviere-Lorphevre, Enrico Filippi.Finite element prediction of the tool wear influence in Ti6Al4V machining[J]. ScienceDirect Procedia CIRP 31 ( 2015 ) 124 - 129

[4]. JIANG Zenghui,WANG Linlin, SHI Li etc.Study on Tool Wear Mechanism and Characteristics of Carbide Tools in Cutting Ti6Al4V[J].Journal of Mechanical Engineering,

2014.01: 178-184

[5]. GUAN Shan,YAN Lihong,PENG Chang.Application Journal of Mechanical Engineering Application of Regression Algorithm of LS-SVM in Tool Wear Predication[J].Chinese Mechanical Engineering.2015.1,26(2) [6]. SUN Huibin,NIU Weilong,WANG Junyang.Tool Wear Feature Extraction Based on Hilbert-Huang Transformation[J].Journal of Vibration and Shock.2015,24(3)

[7]. PENG Ruitao,ZHANG Cheng,TANG Xinzi etc.DEM Simulation and Experimental Study of Tool Wear in Prestressed Cutting Process[J].Mechanical Science and Technology for Aerospace Engineering.March 2015,Vol.34,NO.3

[8]. QIN Guohua,XIE Wenbin,WANG Bimin.Detection and Control for Tool Wear Based on Neural Network and Genetic Algorithm[J].Optics and Precision Engineering.May.2015,23(5)

[9]. ZHANG Erqing,FU Pan,LI Weilin.Tool Wear Condition Assessment Based on Incomplete Priori 
Knowledge[J].Mechanical Science and Technology for Aerospace Engineering.May.2015.3,34(3)

[10]. D. Philip Selvaraj, P. Chandramohan, M. Mohanraj.Optimization of surface roughness, cutting force and tool wear of nitrogen alloyed duplex stainless steel in a dry turning process using Taguchi method[J].Measurement 49 (2014) 205-215

[11]. Bin Li.On the use of fractal methods for the tool flank wear characterization[J].Int. Journal of Refractory Metals and Hard Materials 42 (2014) 221-227

[12]. Rajiv Kumar Yadav, Kumar Abhishek, Siba Sankar Mahapatra.A simulation approach for estimating flank wear and material removal rate in turning of Inconel 718[J].Simulation Modelling Practice and Theory 52 (2015) $1-14$

[13]. Lei Wan, Dazhong Wang.Numerical analysis of the formation of the dead metal zone with different tools in orthogonal cutting[J].Simulation Modelling Practice and Theory 56 (2015) 1-15.Contents lists available at ScienceDirect

[14]. M.R. Movahhedy, ALE simulation of chip formation in orthogonal metal cutting process, $\mathrm{Ph} . \mathrm{D}$. thesis, University of British Columbia, Institute ofMechanical Engineering, Vancouver, 2000, pp. 33-38.

[15]. K. Al-Athel, M. Gadala, The use of volume of solid (VOS) approach in simulating metal cutting with chamfered and blunt tools, Int. J. Mech. Sci. 53(2011) 23-30.

[16]. Jianzhong LU, Jianing SUN, Metal cutting theory and cutting tools, Int. D.China machine press. Published July 2011,Page from:56-57.

[17]. Keyvan Hosseinkhani, E. Ng, A Combined Empirical and Numerical Approach for Tool Wear Prediction in Machining, Int. J.Available online at www.sciencedirect.com Procedia CIRP 31 ( 2015 ) 304 309.

\section{BIOGRAPHY}

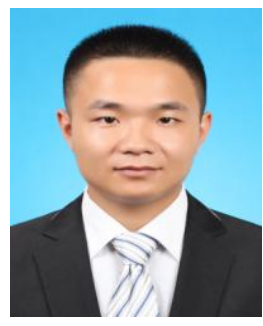

Heyao Shen, The author is a graduate student at Shanghai University of Engineering Science and mainly engages in the research of cutting tools. Email:315857377@qq.com 